\title{
ANTECEDENTES HISTÓRICOS DE LA EDUCACIÓN DE PADRES EN MÉXICO
}

María Teresa Carreras Lomeli

\section{LA EDUCACIÓN DE LOS HIJOS EN LA ÉPOCA PRECORTESIANA}

En la sociedad prehispánica la educación estaba a cargo de la madre: ella se encargaba del desarrollo educativo y físico de los hijos. Desde el momento en que nacía, el niño o la niña se consagraba a una actividad específica para que la idea de función social y educación familiar se complementaran.

Los niños permanecían con sus padres aproximadamente hasta los siete años; después, en su adolescencia, eran llevados al Calmécac o al Tepochcalli.

Las niñas también eran conducidas a algún templo para consagrarse al cuidado del mismo o ser educadas para el matrimonio. La educación se dirigía principalmente a mantener las costumbres y, sobre todo, el desarrollo de virtudes y hábitos que la sociedad practicaba. Todo, como en la mayoría de las sociedades, era objeto de inculcación y educación: el modo de vestir, dialogar, caminar, etcétera, así como el importante respeto debido a los mayores y a los antepasados.

Un ejemplo lo encontramos en la obra titulada "Huehuehtlahotolli" cuyo significado evoca los testimonios de la antigua palabra de los nahuatls. Palabra que pasó de generación en generación, transmitiendo las costumbres, tradiciones, simbolismos, idiosincrasia, creencias y modo de vivir del México prehispánico. Pero, además, la palabra antigua ofrecía una gran riqueza, puesto que representó la guía espiritual y moral del pueblo nahuatl: grandes enseñanzas que los ancianos compartieron con los pupilos por medio de códices. Padres y maestros hicieron uso de éstos, entregando la antigua palabra a sus hijos y alumnos con el fin de alcanzar la sabiduría y la plenitud. 
En el hogar, como en la escuela, eran enseñados y aprendidos estos mensajes llenos de experiencia y sabiduría.

Aquí entraba en acción -en la preservación y transmisión de la antigua palabra-, el papel del sabio o tlamatini. Éste se encargaba de difundir los códices que mostraban diversos aspectos como los cómputos del calendario, cantares prehispánicos, destinos humanos, crónicas históricas y registros acerca de la divinidad.

La formación de este gran sabio puede comprenderse mejor con el siguiente fragmento del códice florentino:

El sabio verdadero es cuidadoso y guarda la tradición.

Suya es la sabiduría transmitida, él es quien la enseña, sigue la verdad.

Maestro de la verdad, no deja de amonestar.

Cualquiera es confortado por él, es corregido, es enseñado.

Gracias a él, la gente humaniza su querer y recibe una estricta enseñanza

Confronta el corazón, confronta a la gente, ayuda, remedia, a todos cura ${ }^{1}$.

El sabio, en suma, tenía por misión guiar o enseñar el camino que había de seguir el hombre.

En el siglo XVI, los misioneros españoles contribuyeron notablemente a preservar la antigua palabra, apreciando la belleza de la cultura indígena y decidiendo recuperar sus elementos más valiosos.

Los "Huehuehtlahtolli" contienen las conversaciones antiguas que los padres y madres transmitieron a sus hijos e hijas, y los señores a sus vasallos; todos ellos están llenos de una doctrina moral y política. Han sido clasificados de acuerdo a la temática que abordan:

$\sim$ Los referidos a los momentos fundamentales de la vida: nacimiento, dedicación a la escuela, matrimonio, embarazo, enfermedad y muerte.

${ }^{1}$ LEÓN PORTILLA, M. Huebuehtlabtolli II. Testimonio de la antigua palabra., p.9-10. 
$\sim$ Los que tratan aspectos de gobierno y orden sociopolítico.

$\sim$ Los concernientes a las pláticas de determinadas ocupaciones: médicos, artesanos, mercaderes...

$\sim$ Los relativos a otros aspectos, como la cortesía, discursos y oraciones a distintos dioses prehispánicos.

De acuerdo a los diversos temas que giran en torno a la educación familiar, retomaremos la palabra antigua, referida a los consejos y educación que los padres y madres confían a sus hijos e hijas.

\section{Plática entre el padre y su hija, llegada la edad de la reflexión}

Estos diálogos giran en torno a los consejos que el padre ofrece a su hija, una vez que ésta ha adquirido la capacidad para razonar y comprender la antigua palabra. Aunado a esto, el padre presenta a su hija una filosofía del mundo:

Mi hijita... mi plumaje de quetzal, mi hechura humana, en ti está mi imagen.

Ahora que miras por ti misma, date cuenta. Aquí es de este modo: no hay alegría, no hay felicidad. Hay angustia, preocupación, cansancio. Por aquí surge, crece el sufrimiento, la preocupación. Es este lugar donde casi perece uno de sed y de hambre. Así es aquí en la tierra.

Así andan diciendo los viejos: para que no siempre andemos gimiendo, para que no estemos llenos de tristeza, el Señor Nuestro nos dio a los hombres, la risa, el sueño, los alimentos, nuestra fuerza y nuestra robustez y finalmente el acto sexual, por el cual se hace siembra de gentes.

Hay afán, hay vida y hay lucha, hay trabajo, se busca mujer, se busca marido.

Como vemos, se habla de la condición del hombre en la tierra. Lugar donde se sufre, se llora y se pena; sin embargo, 
no por ello se ha de estar lamentando, pues es necesario continuar el camino para cumplir la misión que Dios ha confiado. En pocas palabras, esto es lo que el padre dice a su hija.

Para aminorar el peso de la vida en la tierra y guiarse por el camino de la rectitud, el padre le expresa a la hija una serie de consejos:

- Andar el camino de la rectitud.

- Ser respetuosa con los padres y no mofarse de ellos.

- Guardar respeto hacia sí misma y no convertirse en una mujer pública.

- Elegir con seriedad al compañero y vivir con él hasta el último día.

También la madre recomienda la palabra que el padre le confió para transmitirla a sus hijos, para guiarlos por el buen camino:

Ahora mi niña, tortolita, tienes vida, has nacido, has salido, has caído de mi seno, no andes sufriendo por la tierra.

Porque en lugares peligrosos, en lugares espantosos, con gran dificultad se vive.

Así hay asperezas en la tierra. Porque se acaban los rostros de la gente, los corazones de la gente.

Y, tú, no te abandones, no seas desperdiciada, no te quedes atrás, tú que eres mi collar, mi pluma de quetzal. No se dañe tu rostro, tu corazón.

(...) No te hagas amiga de los mentirosos, de los ladrones, de las malas mujeres, de los entrometidos, de los perezosos, para que no te roñan, para que no te hechicen, sólo dedícate dentro de casa a lo que vas a hacer $(. . .)^{2}$.

${ }^{2}$ Ibidem p.16-17. 


\section{La charla entre el padre y el bijo casado}

Lo que se aborda en este testimonio son las encomiendas que el padre transmite a su hijo casado entre las cuales destacan las siguientes:

- Cuidar o velar por su esposa orientándole por el camino del deber e instruyéndola en los trabajos propios de la mujer.

- Honrar y guardar las sabias palabras del padre y la madre, para que el buen nombre de éstos se conserve.

- Sustentar el hogar con gran esmero; es decir, no desatender sus obligaciones.

- Enaltecer a la gente y al trabajo.

- Conseguir a los hijos y entregarles la palabra sabia, a fin de que puedan vivir en la tierra respetando al Señor Dios.

- Obedecer y amar a las personas, pues con la reverencia y el acatamiento será amado y obedecido3.

Por los testimonios de la palabra antigua nos podemos dar cuenta de que educar es una tarea que se practicaba cotidianamente por medio de los "Huehuehtlahtolli", donde los padres enseñaban a sus hijos el camino para andar sobre el mundo, y los hijos guardaban con gran devoción estos consejos que se les habían confiado.

Las pláticas entre padres e hijos, madres e hijas denotan las peculiaridades de una doctrina religiosa, moral y educativa por la cual se pretendía guiar, observar y aconsejar a los hijos en distintos momentos de su vida. Sociedad y vida familiar estaban integradas, al punto en que la primera parecía la resultante inevitable de esa filosofía social y familiar: lo social se originó en la educación.

\section{LA EDUCACIÓN FAMILIAR EN LA NUEVA ESPAÑ̃}

La educación en la Nueva España se encauzó a la implantación de nuevos patrones culturales buscando, principalmente, integrar a los individuos a la actividad y al grupo social

${ }^{3}$ Ibidem p.91-98. 
correspondiente. Aparentemente había esperanzas en que la educación mejorara a las personas.

"Los padres en sí que eran responsables de orientar la educación, se enfrentaban una vez más al eterno dilema de mantener las tradiciones e inculcar a los niños las veneradas costumbres de los tiempos pasados, o enseñar a sus alumnos y aprender de ellos mismos a vivir en el mundo que les rodea o aún mejor prepararse para lo que el futuro les deparaba ${ }^{4}$.

Los niños y jóvenes se educaban en un ambiente que respetaba las viejas normas, pero eran atraídos por las nuevas corrientes de pensamiento llegadas de Europa a través de los textos políticos y filosóficos que para la autoridad representaban una gran peligrosidad. Para contrarrestar la mala influencia de tales lecturas, se recomendaba la lectura de libros piadosos.

Como ha de esperarse en una sociedad en formación, durante este período la educación era cerrada a los cambios culturales e ideológicos, se aferraba a sus tradiciones y antiguos preceptos, por lo que se ganaba muy poco en independencia y formación cultural.

\section{LA EDUCACIÓN FAMILIAR EN LA ÉPOCA POST REVOLUCIONARIA}

La figura de José Vasconcelos jugó un papel importante. En 1920 impulsó, desde la Secretaría de Educación Pública, un amplio programa de alfabetización que dejaba ver, entre líneas, su preocupación por una especie de educación para padres. Ésta sería proporcionada por profesores honorarios, quienes estaban encargados básicamente de generar hábitos de limpieza en sus alumnos. La higiene y los hábitos del buen comer empezaron a aparecer en las prioridades nacionales. La idea básica era que el gobierno tomara parte en esa formación de hábitos y costumbres, no académicas, que la escuela no había podido cubrir. La destinataria de todo este movimiento era, obviamente, la madre de familia.

4 GONZALBO, P., Las mujeres en la Nueva España, Educación y vida cotidiana. p. 278 . 
La campaña llega al punto de reformar el artículo 3o , para dar lugar al proyecto en el cual se enfatizaba el deber de alimentar y educar a los hijos por parte de los padres. El objetivo general era "infundir sanos principios morales, propagar la higiene y preparar buenos ciudadanos y hombres dignos ". $\mathrm{Pa}-$ ra todo esto había que mejorar, primero, las relaciones entre padres de familia y profesores.

Es en este tiempo que surgen los problemas de organizar la educación en el México posrevolucionario. En esta época se percibía la educación como agente de cambio para el desarrollo nacional.

La educación en la familia era responsabilidad, principalmente, de la mujer. A ella se le encomendaban los objetivos de formación de los hijos, ya que era quien estaba en el hogar y con quien éstos más compartían. Se hacía hincapié en el objetivo de formar hombres y mujeres para el hogar... "La instrucción y la educación es arma moral e intelectual que aquí se adquiere y servirá luego para (...) formar con nuestros hogares el hogar nacional, el hogar mexicano" ${ }^{6}$.

Otro de los aspectos que destacaba era donde mencionaba que "aquellas mujeres que asistían a la escuela tendrían más armas para formar mejor a sus hijos ${ }^{7}$. La mujer instruida y educada será la verdaderamente propia para el hogar, para ser la compañera, la colaboradora del hombre en la formación de la familia.

Todo esfuerzo por educar a la mujer iba dirigido a evitar que los lastres dejados por la violencia, la anarquía social y política generada por la revolución, arraigaran en la sociedad e impidieran una transmisión hacia la república deseada.

Hacia 1936, el Estado Mexicano fundó su autoridad y su vinculación con la educación familiar, retomando muchas de las enseñanzas desarrolladas en la Unión Soviética.

5 TELL, C., José Vasconcelos, los años del Águila. 1920-1925. p.62.

${ }^{6}$ SIERRA, J., Obras completas. Tomo VIII. p.329.

${ }^{7}$ Idem. 
Trabajo, limpieza, orden, colectivismo, eran los dogmas socialistas y también las premisas de trabajo del presidente Lázaro Cárdenas, franco amigo de la Unión Soviética; la influencia de Makarenko era clara en la política social y educativa del gobierno socialista de Cárdenas, quien también se ocupó de la educación de los padres de familia.

Al igual que en muchos países europeos, la modalidad de la educación familiar se originó en México por el grave problema de abandono a los hijos, la delincuencia y la mortandad infantil; la causa de este abandono era la desorganización familiar y la falta de interés de los padres para con sus hijos.

Todos los malos comportamientos de los niños obedecían -se decía- a que "los padres estaban dedicados a actividades antisociales y los niños recibían el ejemplo nocivo de sus mayores" ${ }^{8}$.

Entre las soluciones planteadas en esta época se contaban: dejar a los niños en manos de la beneficencia; apelar al artículo 382 del código civil para obligar a los padres a que alimentaran a sus hijos; ayudar con granos y/o dinero a aquellos padres que enviaran a sus hijos a la escuela a fin de prepararlos para la vida. (Actualmente el Estado continúa con las políticas de ayuda material a algunas familias para que sus hijos asistan a la escuela mediante los programas sociales). También se realizaban campañas y programas dirigidos principalmente a las madres de familia de la zona rural, con la finalidad de convencer a la mujer mexicana de los beneficios del sistema y del importante papel que desempeñaba para el alma nacional.

\section{ACTUALIDAD Y PROSPECTIVA}

La participación de los padres de familia en la escuela, se ha venido propiciando desde 1929, aunque fue hasta 1933 cuando Abelardo Rodríguez expidió el reglamento de padres de familia en el Distrito Federal. El documento era un reconocimiento a la necesidad de organizar la representación de las

${ }^{8}$ Idem. 
personas que ejercían la patria potestad, tutela o representación reglada de los menores ante las autoridades educativas correspondientes?.

Para 1980, con José López Portillo, se propuso otro reglamento que normaba la asociación de padres. El objetivo de estos proyectos era formar hombres y mujeres capaces de alcanzar el éxito personal y profesional, ser felices y educar en el amor y el servicio, formando así una sociedad más sana y justa que lograra un mayor desarrollo como nación.

A principios de los ochenta, la SEP publicó un manual para padres de familia de los niños de primero, con la finalidad de informar sobre los cambios del nuevo programa integrado e invitarlos a tener una participación más activa en la formación escolar de sus hijos, y promover programas para atención a los padres de los niños de preescolar.

Hacia finales de esa década, se hizo más patente la necesidad de impulsar centros públicos y privados, así como generar políticas gubernamentales propicias para educar a los padres con respecto a ciertos aspectos funcionales de la sociedad.

El Estado mostró verdadero interés en que los padres se prepararan e involucraran educativamente en la formación de los hijos, pues esto podía representar ahorros en gastos de salud, y en la prevención y tratamiento de males sociales (adicciones, vandalismo, etcétera).

A pesar de ello, ha sido la sociedad civil la que mejor ha sabido promover tales políticas de sensibilización sobre la formación de mejores ciudadanos.

A través de ella, diversas instituciones, asociaciones civiles e incluso iglesias, representaron todo un cambio en la comprensión del papel de los padres en la formación integral de sus hijos.

Podemos afirmar que, actualmente, los padres y las madres de familia han estado reasumiendo la responsabilidad en la formación y educación de sus hijos. Para esto se ha tenido

"CASADO, P., "La escuela y los padres de familia" en Revista Mexicana de Pedagogía. Enero-febrero, 99. Vol. 10. p.6. 
que recurrir a campañas para animar a otros padres a estar más cerca de sus hijos y de la escuela, con tal de lograr una mejor participación social. Hoy son muchas las instituciones privadas y públicas ocupadas en desarrollar programas educativos dirigidos a los padres de familia orientados a desarrollar mejor su función.

Hasta donde sabemos, no existen estudios sistematizados que hubieran obtenido un claro consenso sobre la educación de padres en México. Sin embargo, el hecho de que se haya convertido en problemática la necesidad de educar a los padres como formadores básicos de sus hijos, ha cohesionado las investigaciones en este campo.

La clásica división: impartición de conocimientos científicos (escuela) por un lado y formación útil para la vida en el hogar y en la sociedad (educación familiar), hizo obvio el que no bastaba la buena voluntad de los padres o la pura entrega de afecto, para que este conocimiento sobre el entorno existente, fuera del núcleo familiar, se asumiera por los niños y adolescentes como expresión de un compromiso humano y social.

El conocimiento de las relaciones familiares, así como la influencia de los padres en la formación de la personalidad de los hijos, fueron objeto de investigación y estudio por parte de varias ciencias y disciplinas, y fundamento para la propuesta de proyectos de educación familiar. Ello planteó que la afectividad fuera considerada de vital importancia en las posibilidades de lograr objetivos educativos.

Si bien hace 150 años ${ }^{10}$ se ha buscado implantar la sistematización de medidas educativas para los padres, sobre todo en países como Francia, España e Inglaterra, México ha demostrado no estar tan a la zaga en relación a estas propuestas. Cuando filósofos y pedagogos europeos del siglo XVI propalaban sus ensayos sobre cómo educar a los hijos, las narraciones prehispánicas hacían hincapié en el amor y el cuidado que debían tener los padres, así como en el respeto a las ${ }^{10}$ STERN, H., La educación de los padres. p.29. 
decisiones de los hijos pues éstos, se decía, por muy pequeños que estuvieran, sentían y discernían el trato que les daban sus padres. Esta continua alusión, en el contexto mexicano, a la ternura, amor, aptitudes y albedríos, afirma esa necesidad de considerar el aspecto afectivo como uno de los ejes fundamentales para la futura formación de niños y adolescentes.

A lo largo de la historia han aparecido ciertas constantes en las recomendaciones a los padres para educar a sus hijos, así como la educación propiamente para padres y madres. Sería necesario rescatarlas y sistematizarlas con el objeto de ofrecer a éstos una educación más sólida y con un mayor respaldo conceptual y metodológico. Es altamente recomendable proponer para los padres y madres una formación que incluya todos los aspectos educativos de la vida cotidiana.

La historia real -de desajustes sociales, resentimiento familiar, bajo rendimiento escolar-, ha demostrado que las creencias de una educación familiar o escolar basada en la consideración de que los niños son elementos pasivos en quienes hay que depositar mecánicamente valores y conocimientos, no favorecen el buen desarrollo de los niños y adolescentes.

Algo no ha funcionado en el ejercicio de estas concepciones educativas, como también algo falló en las concepciones de origen roussoniano en las que se apuesta a la libertad del niño, sin límites claros, para que éste llegue por sí solo a alcanzar su plenitud.

La realidad irrumpe, más tarde que temprano, demostrando las consecuencias nocivas de concepciones educativas enviciadas y llevadas a los extremos y revela, asimismo, las posibilidades de una educación integral de los niños en todos sus aspectos: físico, social, afectivo, intelectual y espiritual, donde el amor y la libertad juegan un papel tan importante como la disciplina.

De acuerdo con la revisión documental realizada, en relación a la historia de la crianza y educación de los hijos en la familia, así como a la orientación familiar y surgimiento de las 
escuelas para padres, se puede afirmar que a lo largo de los años han aparecido ciertas constantes en la educación de los padres y de los hijos que resulta necesario reconsiderar y recrear en la actualidad. Dichas constantes son:

- Vivir, conservar y transmitir los valores religiosos.

- Preservar, mantener y recrear los valores tradicionales y costumbres propias de la familia.

- Cuidar y mantener la salud e higiene mental y física de los miembros de la familia.

- Relacionarse y cooperar activamente con la escuela de los hijos.

- Administrar y cuidar el hogar.

- Recrear y aprovechar el tiempo libre.

- Contribuir al mejoramiento del ambiente natural y social.

Tomar en cuenta estos aspectos que han venido dándose a lo largo de la historia y que, en un momento dado, han respondido a las necesidades sociales de cada época, nos lleva a afirmar que si se presentan como contenido curricular de una educación sistemática e integral para padres y madres de familia, éstos podrán realizar mejor y con más seguridad su delicada tarea de formar personas maduras y ciudadanos responsables.

Todo proceso educativo en el niño gira en torno a la formación de su personalidad y tiene como fin último el ejercicio responsable de la libertad. Lo que recibe implícita y explícitamente de sus padres, condicionará qué tipo de persona será en el futuro.

De allí la importancia que los padres tengan bien cimentada la propia personalidad para que, naturalmente, la ofrezcan a sus hijos puesto que una educación basada en el amor, la disciplina y la libertad proporciona la confianza y seguridad que el niño requiere para su desarrollo. 


\section{BIBLIOGRAFÍA}

CASADO, Pilar. "La escuela y los padres de familia" en Revista Mexicana de Pedagogía. Director Humberto Pérez Talabera. Enero-febrero, vol. 10 no. 45. México, 1999.

CHÁVEZ, Ezequiel. La educación en México en la época precortesiana. Editorial Jus. México, 1958.

GONZALBO AIZPURU, Pilar. Las mujeres en la Nueva España. Educación y vida cotidiana. El Colegio de México. México, 1987. 324 p.

LEÓN PORTILLA, Miguel. Huebuebtlabtolli. Testimonio de la antigua palabra. FCE- SEP. México, 1991.

SIERRA, Justo. Obras completas. La educación nacional articulos, actitudes y documentos. Tomo VIII Edición y notas de Agustín Yáñez. UNAM. México, 1948.

STERN H., H. La educación de los padres. Ed. Kapeluz, Buenos Aires, Argentina, 1967.

TELL, Claudel. José Vasconcelos, los años del águila. 1920.1925. 1989. 